Andrew C. Argent Simon Nadel

\title{
Big babies and big adults surprise us by their outcomes: why?
}

Received: 15 July 2014

Accepted: 5 August 2014

Published online: 3 September 2014

(C) Springer-Verlag Berlin Heidelberg and ESICM 2014

\section{A. C. Argent $(\square)$}

School of Child and Adolescent Health, University of Cape Town, Klipfontein Road, Rondebosch, Cape Town 7700, South Africa

e-mail: andrew.argent@uct.ac.za

Tel.: +27216585369

A. C. Argent $\cdot$ S. Nadel

Paediatric Intensive Care Unit, Red Cross War Memorial Children's Hospital, Klipfontein Road, Rondebosch, Cape Town 7700 , South Africa

S. Nadel

Paediatric Intensive Care, St Mary's Hospital and Imperial College, Praed Street, London W2 1NY, UK

The relationship between body mass index (BMI) and mortality in adults is in general a U-shaped one with higher mortality in both underweight and obese people [1], although cause-specific mortalities are different in different BMI categories, and data may be substantially affected by the definition of the categories [2]. Being underweight may reflect recent weight loss, severity of illness and possibly malnutrition which may all contribute to increased mortality. While obesity (and particularly severe obesity) has been associated with increased mortality and morbidity, a recent meta-analysis suggested that people with class 1 obesity (BMI 30 to less than $35 \mathrm{~kg} / \mathrm{m}^{2}$ ) had a lower risk of mortality [2].

In the critical care context surgical patients with low BMI have increased in-hospital mortality [3]. Some studies report that obesity is related to worse ICU outcomes $[4,5]$, while others report the reverse [3]. A recent meta-analysis concluded that while obesity was associated with prolonged ventilation and ICU stay, it was not associated with increased mortality [4] and patients in the weight category of BMI $30-39.9 \mathrm{~kg} / \mathrm{m}^{2}$ had a lower ICU mortality compared to non-obese patients. However there are different patterns of obesity and abdominal obesity (as assessed by measures such as waist hip ratio, waist circumference and weight to height ratio) [1] may have different implications to "general obesity". Recent ICU studies suggested that sagittal abdominal diameter may accurately predict both organ failure and mortality [6].

Allocation of BMI categories may be suboptimal in the ICU [7] with more than $20 \%$ of patients changing categories if fluid balance prior to ICU admission is taken into account. There may be a range of causes of BMI at the extremes, and it is interesting to speculate that patients may require different clinical approaches. Recently low nutritional intake during the first week of admission was associated with reduced duration of ventilation in patients with low BMI [8]. It has also been suggested that patients with a high BMI might have relatively low transpulmonary pressures during mechanical ventilation which may confer some protective effects. Despite this data, it seems likely that the majority of ICU patients are not weighed on admission, weights are estimated and size is not included in all considerations of care. Do patients at the extremes of the BMI spectrum require a more detailed diagnostic approach to nutritional status together with a nuanced approach to therapies such as nutritional intake, tidal volumes on ventilation and drug dosing for antibiotic therapy?

In a recent issue of Intensive Care Medicine, Prince et al. [9] reviewed the relationship between admission weight for age and paediatric intensive care unit (PICU) outcome in a data set of 14,307 admissions to the neonatal and paediatric intensive care unit at Great Ormond Street 


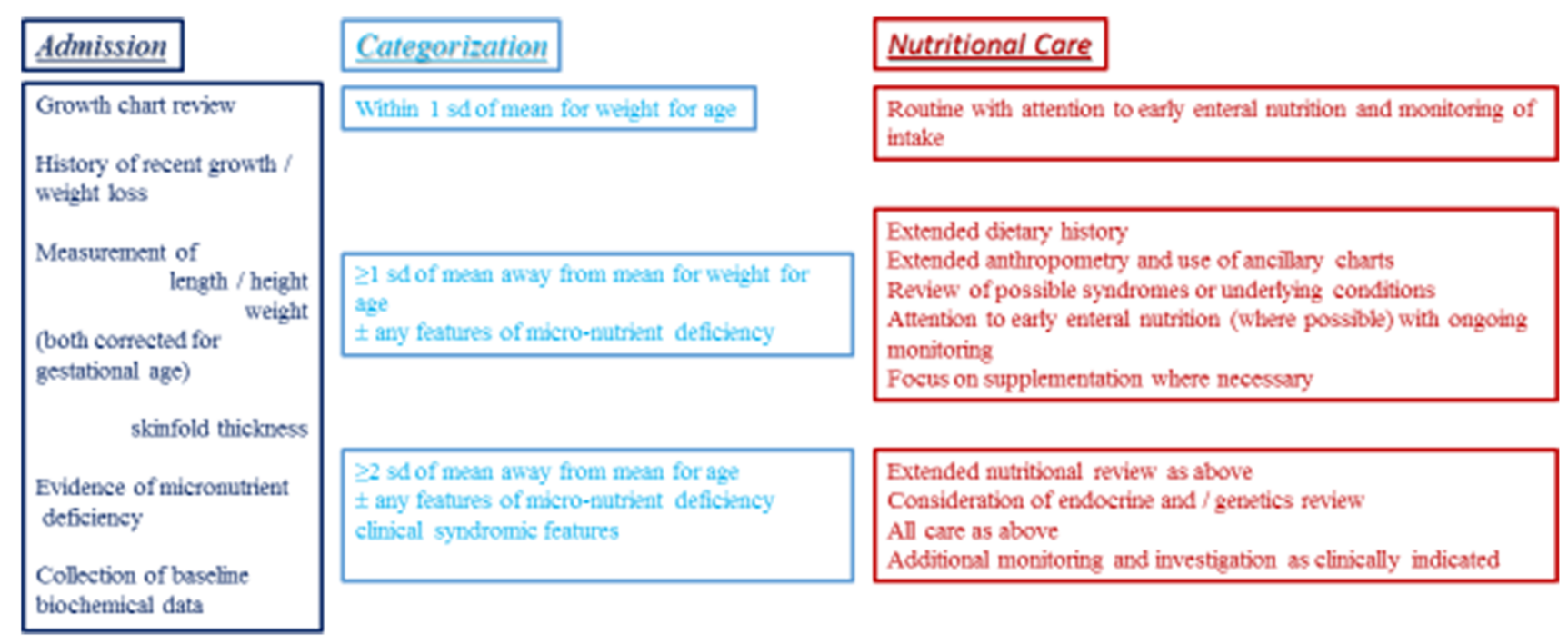

Fig. 1 Potential approach to nutritional management in the PICU. This outline could provide a basic outline to both data collection and clinical care in the PICU

Hospital in London. The key findings were that the mean weight for age for the PICU was significantly lower than the UK population mean; that patients with highest and lowest categories of weight for age (difference between the child's weight and the UK mean for age is more than 3.5 standard deviations) had the highest mortality; and the patients in the mild to moderately overweight for age category had the lowest mortality. This finding is in keeping with previous paediatric data from Australia [10] (where Numa et al. also reported a "U-shaped" mortality curve when related to weight for age centiles); from the USA [11] where obesity was not associated with increased mortality or morbidity and from Denmark where low weight was a predictor of mortality following cardiac surgery [12].

It is not clear what the implications of low weight for age on admission are. The weight for age must be compared to appropriate standards, taking into account factors such as prematurity, ethnic differences and underlying syndromes such as chromosomal abnormalities. In this study, age was corrected for prematurity, but no allowances were made for any of the other confounders, e.g. underlying syndromes (in the Australian study approximately $7 \%$ of patients had underlying syndromes [10]). In many studies a low weight for age has been taken as diagnostic of malnutrition, but as pointed out by Mehta et al. [13] a comprehensive definition of malnutrition in critically ill children remains elusive. Patients may be underweight or overweight for age for a wide variety of reasons including malnutrition (primary or secondary to malabsorption or nutritional losses); underlying congenital syndromes; endocrine disorders (such as pituitary or adrenal problems); underlying disease (including cardiac or renal disease). This is particularly true of the cohort of children being admitted to intensive care in tertiary referral centres with a high incidence of complex disorders, underlying co-morbidities and other conditions.

There is an urgent need for studies which elucidate the specific role of nutrition in critically ill children. A starting point would be the outlining of parameters which should be measured in order to assess the nutritional status of the child (Fig. 1). The diagnosis of malnutrition in adults can be based on six different areas: (1) insufficient food and nutrition intake relative to predicted requirements, (2) weight loss over time, (3) loss of muscle mass, (4) loss of fat mass, (5) fluid accumulation, and (6) measurably diminished grip strength [14]. However anthropometry in critically ill children may be inaccurate. Much of the other data is simply not available on PICU admission unless efforts are very specifically directed at collection.

Despite the fact that size clearly matters (in both adults and children), it seems that we are poorly equipped to measure size accurately (and meaningfully). Accurate weight, length and skinfold thickness are rarely if ever measured on PICU admission, particularly in those admitted as an emergency, let alone during the PICU stay. In addition, there is good data that following admission, inadequate nutrition is almost universal and critically ill patients often become malnourished within a short period of time, with some evidence that this impacts on outcome [15].

There are numerous publications on the nutritional care of patients in ICU, but we seem to find it difficult to understand some very basic issues regarding the nutritional status and requirements of our patients. It is not surprising that much data regarding size and outcome is labelled as "paradoxical", yet much crucial information 
could be rapidly gathered if we actually paid attention to "nutritional" measurement in both adults and children.
Conflicts of interest On behalf of all authors, the corresponding author states that there is no conflicts of interest.

\section{References}

1. Carmienke S, Freitag MH, Pischon T, Schlattmann P, Fankhaenel T, Goebel H, Gensichen J (2013) General and abdominal obesity parameters and their combination in relation to mortality: a systematic review and meta-regression analysis. Eur J Clin Nutr 67:573-585

2. Flegal KM, Kit BK, Orpana H, Graubard BI (2013) Association of allcause mortality with overweight and obesity using standard body mass index categories: a systematic review and meta-analysis. JAMA 309:71-82

3. Hutagalung R, Marques J, Kobylka K, Zeidan M, Kabisch B, Brunkhorst F Reinhart K, Sakr Y (2011) The obesity paradox in surgical intensive care unit patients. Intensive Care Med 37:1793-1799

4. Akinnusi ME, Pineda LA, El Solh AA (2008) Effect of obesity on intensive care morbidity and mortality: a metaanalysis. Crit Care Med 36:151-158

5. Bochicchio GV, Joshi M, Bochicchio K, Nehman S, Tracy JK, Scalea TM (2006) Impact of obesity in the critically ill trauma patient: a prospective study. J Am Coll Surg 203:533-538

6. Chalkias A, Nitsotolis T, Papalexandrou A, Mikros S, Iacovidou N, Xanthos T (2013) Sagittal abdominal diameter may effectively predict future complications and increased mortality in intensive care unit patients with severe sepsis. J Crit Care 28:964-969
7. O’Brien JM Jr, Philips GS, Ali NA, Aberegg SK, Marsh CB, Lemeshow S (2012) The association between body mass index, processes of care, and outcomes from mechanical ventilation: a prospective cohort study. Crit Care Med 40:1456-1463

8. Ichimaru S, Fujiwara H, Amagai T, Atsumi T (2014) Low energy intake during the first week in an emergency intensive care unit is associated with reduced duration of mechanical ventilation in critically ill, underweight patients: a single-center retrospective chart review. Nutr Clin Pract 29:368-379

9. Prince NJB, Brown KL, Mebrahtu TF, Parslow RC, Peters, MJ (2014) Weightfor-age distribution and case-mix adjusted outcomes of 14,307 paediatric intensive care admissions. Intensive Care Med 40:1132-1139. doi: 10.1007/s00134-014-3381-x

10. Numa A, McAweeney J, Williams G, Awad J, Ravindranathan H (2011) Extremes of weight centile are associated with increased risk of mortality in pediatric intensive care. Crit Care 15:R106

11. Goh VL, Wakeham MK, Brazauskas R, Mikhailov TA, Goday PS (2013)

Obesity is not associated with increased mortality and morbidity in critically ill children. JPEN J Parenter Enteral Nutr 37:102-108
12. Larsen SH, Pedersen J, Jacobsen J, Johnsen SP, Hansen OK, Hjortdal V (2005) The RACHS-1 risk categories reflect mortality and length of stay in a Danish population of children operated for congenital heart disease. Eur J Cardiothorac Surg 28:877-881

13. Mehta NM, Corkins MR, Lyman B, Malone A, Goday PS, Carney LN, Monczka JL, Plogsted SW, Schwenk WF (2013) Defining pediatric malnutrition: a paradigm shift toward etiology-related definitions. JPEN J Parenter Enteral Nutr 37:460-481

14. White JV, Guenter P, Jensen G, Malone A, Schofield M (2012) Consensus statement: Academy of Nutrition and Dietetics and American Society for Parenteral and Enteral Nutrition: characteristics recommended for the identification and documentation of adult malnutrition (undernutrition). JPEN J Parenter Enteral Nutr 36:275-283

15. Mehta NM, Bechard LJ, Cahill N, Wang M, Day A, Duggan CP, Heyland DK (2012) Nutritional practices and their relationship to clinical outcomes in critically ill children-an international multicenter cohort study. Crit Care Med 40:2204-2211 